\title{
Entre la historia y la literatura: las Iradiciones Peruanas de la Segunda Serie
}

\author{
Pedro Díaz Ortiz \\ Instituto Ricardo Palma/Universidad Ricardo Palma \\ tarmapap@yahoo.es
}

\section{Resumen}

La relación entre literatura e historia es una de las constantes de la literatura hispanoamericana desde el siglo XVI. En este trabajo exponemos la forma cómo dispuso Ricardo Palma esta relación en las cuarenta y dos tradiciones que conforman la Segunda Serie de las Tradiciones Peruanas.

Palabras clave: historia, literatura, tradición, Ricardo Palma.

\begin{abstract}
The relationship between literature and history is one of the main subjects of the Hispano-American literature since the XVI century. In this paper we present the way in which Ricardo Palma shows this relationship in the forty two traditions of the second part of Peruvian Traditions.
\end{abstract}

Keywords: history, literature, tradition, Ricardo Palma. 
Pedro Díaz Ortiz, Escritor, traductor, editor. Doctor en Letras por la Universidad Nacional Mayor de San Marcos. Past-Decano de la Facultad de Humanidades y Lenguas Modernas de la Universidad Ricardo Palma, Ex Director de la Revista de la Facultad de Humanidades y Lenguas Modernas (URP). Director de la Serie "Letras Francesas". Ha publicado, entre otras obras, La estética teatral de Valle-Inclán, Un no rompido sueño, Edición crítica de la Primera Serie de Tradiciones Peruanas, de Ricardo Palma, Albert Camus. Teatro y sociedad, y Gaudeamus. Ha realizado diversas traducciones de poesía francesa, entre otras de Blaise Cendrars, Raymond Queneau, Georgette Vallejo y André Coyné. 
El descubrimiento y la conquista de América propiciaron el surgimientodelos primeros géneros literarios hispanoamericanos: la crónica y la épica, cuyo inicio se dio a partir de la necesidad de describir tierras y pueblos hasta entonces desconocidos y de narrar su sometimiento y conquista. Arturo Torres-Ríoseco dice al respecto: "Había que escribir la historia viva y así nació la crónica. Había que cantar grandes hazañas y así se engendró la epopeya. Estos dos géneros, la crónica y la épica, fueron, pues, el comienzo de la literatura hispanoamericana." (1945: 11). Por su parte, Raúl Porras Barrenechea dice: "La crónica es, por naturaleza, un género vernáculo que brota de la tierra y de la historia." (1962: 9).

De los dos géneros literarios, la crónica fue el que alcanzó mayor auge e importancia, razón por la cual el siglo XVI fue denominado el Siglo de las Crónicas. Los cultores de las crónicas fueron principalmente soldados y clérigos. La conquista de las Indias fue una empresa material y espiritual a la vez. Aparecen de este modo dos testimonios, dos versiones. Una, la de los soldados -la crónica soldadesca-, cuyo fin fue realzar y justificar los hechos de la conquista; y la otra, la de los clérigos -la crónica religiosa-, que buscó adoctrinar a los pueblos sojuzgados.

Las crónicas, en su mayor parte, fueron la historia escrita en el mismo momento de los hechos de la conquista, pero si las crónicas son, a su modo, historia, también son literatura en cuanto en ellas aparecen mitos, fábulas y hechos propios más bien de la ficción y no de la realidad. A propósito de esta particularidad de las crónicas, Vargas Llosa dice:

Historia y literatura -verdad y mentira, realidad y ficciónse mezclan en estos textos de una manera inextricable. La delgada línea de demarcación que las separa está continuamente evaporándose para que ambos mundos se confundan en una totalidad que es tanto más seductora 
cuanto más ambigua porque en ella lo verosímil y lo inverosímil parecen una misma sustancia. (1986: 14)

Desde entonces, desde el siglo XVI, historia y literatura andan de la mano en las letras hispanoamericanas, una y otra se nutren de la realidad y de la ficción desde los Comentarios Reales del Inca Garcilaso de la Vega hasta El reino de este mundo de Alejo Carpentier, y otras novelas de la narrativa latinoamericana contemporánea.

Más adelante, en el siglo XIX aparecen, por primera vez, dos géneros literarios genuinamente latinoamericanos: la literatura gauchesca y las Tradiciones Peruanas de Ricardo Palma. Acerca de las tradiciones, Raúl Porras dice: “La ‘tradición’ creada por Palma es un género literario propio e inconfundible que no se amolda ni cabe en los géneros conocidos. Es un producto genuino, limeño y criollo. No es historia, novela, ni cuento, ni leyenda romántica." (1986: 14)

Historia y literatura también se entrecruzan en las Tradiciones Peruanas, pero es en las tradiciones de la Segunda Serie donde estas aparecen delimitadas de acuerdo a lo establecido por Palma. Por esta razón, las tradiciones que conforman la Segunda Serie de las Tradiciones Peruanas (42) revisten un especial interés en el conjunto de la obra de Palma. Al respecto, él mismo, en el prólogo de la segunda edición de la Primera Serie de las Tradiciones Peruanas (1883), dice: “(...) las verdaderas tradiciones empiezan, a mi juicio, en la Segunda Serie.” (Ibíd.: 14)

Si bien Ricardo Palma dice tal idea, hay tradiciones que son tanto o más representativas del estilo palmista como Don Dimas de la Tijereta, que forma parte de la Primera Serie de las Tradiciones Peruanas. Hecha esta salvedad, podemos decir que la afirmación palmista es acorde con una innovación sui generis que Palma introdujo en la literatura al hacer de esta no solo 
el campo per se de la ficción, sino también de la historia. Esta percepción motivó, sin duda, su intención en torno a lo que debía ser la tradición como género literario: ficción e historia a la vez, tal como ocurre en las tradiciones de la Segunda Serie.

Las tradiciones de la Segunda Serie están divididas en partes o capítulos como los llama Ricardo Palma. En cada una de estas partes, divididas por números romanos, Palma alterna los sucesos novelescos con los hechos históricos más importantes que ocurrieron en cada uno de los gobiernos de los gobernantes y virreyes que rigieron al Perú desde la guerra civil de los conquistadores hasta los últimos sucesos del virreinato. Así, por ejemplo, en las partes I y III de la tradición La monja de la llave (Crónica de la época del sexto y séptimo virreyes del Perú), Palma presenta el amor trágico de la bella limeña Violante de Ribera con el capitán de escopeteros Rui Díaz de Santillana (el suceso novelesco); y en la parte II, que se inicia con la frase Echemos, lector, el obligado parrafillo histórico, Palma presenta los hechos históricos más importantes acaecidos en los gobiernos de Martín Enríquez, sexto virrey, y Fernando de Torres y Portugal, conde de Villardonpardo, séptimo virrey del Perú.

La referencia histórica en las tradiciones de la Segunda Serie aparece en general en la parte II, tal como podemos apreciar en las tradiciones Lucas el sacrílego y Las orejas del alcalde. En la primera, en el inicio de la parte II, Palma dice: "Ciñéndonos al plan que hemos seguido en las Tradiciones, viene aquí a cuento una rápida reseña histórica de la época (...)"1; y en Las orejas del alcalde, también en el inicio de la parte II, Palma acota: "Hagamos una pausa, lector amigo, y entremos en el laberinto de la historia, ya que en esta serie de Tradiciones nos hemos

1 Ricardo Palma. Tradiciones Peruanas. Segunda Serie. Lucas el Sacrílego/Crónica de la época del vigésimo nono virrey del Perú. Ed. Cultura Antártica. Lima, 1951, p. 292. 
impuesto la obligación de consagrar algunas líneas al virrey con cuyo gobierno se relaciona nuestro relato"2.

En cuanto al carácter de la historia que aparece en las tradiciones de la Segunda Serie, en la parte I de la tradición El encapuchado, Palma dice: "Nuestra pluma es humilde y se consagra solo a hechos reales e históricamente comprobados como el actual, que ocurrió siendo decimosexto virrey del Perú por su majestad don Felipe IV el excelentísimo señor conde de Salvatierra."3

De este modo, Palma establece la estructura de las tradiciones de la Segunda Serie, en la mayoría de las cuales la referencia histórica aparece en la parte II, pero algunas en la parte I como ocurre en El virrey de los milagros; o en la parte III, en El corregidor de Tinta.

La historia en la obra de Ricardo Palma ha dado lugar a una doble lectura: de un lado hay quienes cuestionan la veracidad de la misma como es el caso de Manuel González Prada; y otros, como Augusto Tamayo Vargas, que sostienen lo contrario.

González Prada en su Discurso en el teatro Olimpo de 1887, dice:

Cultivamos una literatura de transición, vacilaciones, tanteos y luces crepusculares. De la poesía van desapareciendo las descoloridas imitaciones de Bécquer; pero en la prosa reina siempre la mala tradición, ese monstruo engendrado por las falsificaciones agridulcetes de la historia y la caricatura microscópica de la novela. (1978: 9)

Tal apreciación de González Prada y de algunos de sus discípulos y seguidores, respecto al sentido de la historia en las tradiciones,

2 Ricardo Palma. Las orejas del alcalde. Ob. Cit., p. 131.

3 Ricardo Palma. El encapuchado. Ob. Cit., p. 208. 
fue, como sabemos, rectificada por las precisiones que hicieron a su turno Víctor Raúl Haya de la Torre y José Carlos Mariátegui. El primero en una carta dirigida a la revista Sagitario (1925), y publicada en sus Obras Completas bajo el título de La nueva y la vieja generación de intelectuales en el Perú, dice:

(...) he encontrado el valor o el más alto prestigio de la obra de Palma como una crítica formidable a la época colonial, al pasado todo, que la interpretación civilista de la literatura del Perú independiente torció, por saberse parte de ese pasado, interpretándolo como un manriquismo negativo y burgués. (1984: 95).

Por su parte, Mariátegui, en su ensayo El proceso de la literatura, dice: "Pertenece al mismo Haya una precisa y, a mi juicio, oportuna e inteligente mise au point sobre el sentido histórico y político de las Tradiciones." (1980: 47).

Más adelante y de un modo, en nuestra opinión, concluyente, Tamayo Vargas precisó el verdadero sentido de la historia en las tradiciones, especialmente en las que conforman la Segunda Serie, pues dice: "el conjunto de las Tradiciones Peruanas sí es un magnífico escaparate histórico del Perú.” (1973: 132), y que “(...) con las Tradiciones de Palma se puede hacer la auténtica historia del Perú, en cuanto historia es reacción crítica y adentramiento en las condiciones específicas de una cultura." (Ibíd.: 133)

Las lecturas de Haya de la Torre, Mariátegui y Tamayo Vargas que inciden en el carácter crítico de la historia en las tradiciones, puede ilustrarse, por ejemplo, en tradiciones como Los caballeros de la capa, donde Palma para enjuiciar lo que fue y lo que es nuestra historia desde la conquista hasta fines del siglo XIX, e incluso la actual, dice: 
Caídos y levantados, hartos y hambrientos, eso fue la colonia, y eso ha sido y es la república. La ley del yunque y del martillo imperando a cada cambio de tortilla, o como reza la copla:

$$
\begin{gathered}
\text { Salimos de Guatemala } \\
\text { y entramos en Guatepeor; } \\
\text { cambia el pandero de manos, } \\
\text { pero de sonidos, no. }{ }^{4}
\end{gathered}
$$

O en la tradición Los Malditos (Crónica de la época del noveno virrey del Perú), en cuya parte II, en la que aparece la referencia histórica, Palma releva el esfuerzo de los indígenas en pro de su libertad, afirmando: "A la vez en todo el virreinato los indios hacían un supremo esfuerzo para romper el yugo de los conquistadores" ${ }^{5}$, y refiriéndose a estas luchas añade:

En Puno y en los Charcas, las autoridades no descansaban en tomar medidas para estorbar la insurrección que amenazaba hacerse general en el país. Esta leyenda comprueba que a las puertas de Lima estaba en pie la protesta contra la usurpadora dominación. ${ }^{6}$

Y en la tradición El corregidor de Tinta (Crónica de la época del trigésimo tercio virrey), Palma registra los procedimientos tiránicos de los corregidores como Antonio de Arriaga que dieron lugar a la revolución de José Gabriel Condorcanqui, Túpac Amaru II, que, dice Palma: “(...) como es sabido, puso en grave peligro al gobierno colonial. Poquísimo faltó para que entonces hubiese quedado realizada la obra de la Independencia." 7 , y respecto al fin trágico de la revolución de 1780, añade Palma: "Así -dice el

4 Ricardo Palma. Los caballeros de la capa. Ob. Cit., pp. 105-106.

5 Ricardo Palma. Los malditos. Ob. Cit., p. 165.

6 Ricardo Palma. Los malditos. Ob. Cit., p. 166.

7 Ricardo Palma. El corregidor de Tinta. Ob. Cit., p. 326 
deán Funes- terminó esta revolución y difícilmente presentará la historia otra ni más justificada ni menos feliz." 8

En conclusión, en las Tradiciones Peruanas de la Segunda Serie se entrecruzan literatura e historia, siguiendo una constante de la literatura hispanoamericana desde el siglo XVI.

\section{Bibliografía}

González Prada, M (1978). Páginas libres. Lima: Ed. Mercurio, tercera edición.

Haya de la Torre, V. R. (1984). Obras Completas. Tomo I, Lima: Ed. Juan Mejía Baca, tercera edición.

Mariátegui, J. (1980). 7 Ensayos de Interpretación de la Realidad Peruana, Lima: cuadragésima tercera edición.

La Edad del Oro. Crónicas y testimonios de la conquista del Perú (1986) Edición de José Miguel Oviedo. Prólogo de Mario Vargas Llosa. Barcelona: Tusquets/Círculo de Lectores (Colección Biblioteca del Nuevo Mundo 1492-1992).

Palma, R. (1951). Tradiciones Peruanas. Segunda Serie. Tomo I, Lima: Ed. Cultura Antártica.

Palma, R. (1945). Tradiciones Peruanas. Selección y Reseña de la Historia Cultural del Perú, por Raúl Porras Barrenechea, Colección Panamericana, Buenos Aires: Ed. W.M. Jackson.

Porras Barrenechea, R. (1962). Los cronistas del Perú (15281650). Lima: Ed. Grace y Cía.

8 Ricardo Palma. El corregidor de Tinta. Ob. Cit., p. 326 
Tamayo Vargas, A. (1976). Literatura Peruana, Tomo II, p. 133. Lima: Ed. Librería Studium.

Torres-Ríoseco, A. (1945). Nueva historia de la gran literatura Iberoamericana. Buenos Aires: Ed. Emecé.

Recibido el 4 de diciembre del 2017 Aceptado el 7 de enero del 2017 